\title{
Preclinical PET imaging of EGFR levels: pairing a targeting with a non-targeting Sel-tagged Affibody-based tracer to estimate the specific uptake
}

Qing Cheng ${ }^{1 \dagger}$, Helena Wållberg ${ }^{1 \dagger}$, Jonas Grafström² ${ }^{2 \dagger}$, Li Lu$^{2,3}$, Jan-Olov Thorell ${ }^{2,4}$, Maria Hägg Olofsson ${ }^{5}$, Stig Linder ${ }^{5}$, Katarina Johansson ${ }^{1}$, Tetyana Tegnebratt ${ }^{2,4}$, Elias S. J. Arnér ${ }^{1}$, Sharon Stone-Elander ${ }^{1,2,4^{*}} \mathbb{D}$, Hanna-Stina Martinsson Ahlzén ${ }^{1}$, Stefan Ståhl ${ }^{6}$ and Sel-tag imaging project

\begin{abstract}
Background: Though overexpression of epidermal growth factor receptor (EGFR) in several forms of cancer is considered to be an important prognostic biomarker related to poor prognosis, clear correlations between biomarker assays and patient management have been difficult to establish. Here, we utilize a targeting directly followed by a non-targeting tracer-based positron emission tomography (PET) method to examine some of the aspects of determining specific EGFR binding in tumors.

Methods: The EGFR-binding Affibody molecule $Z_{E G F R: 2377}$ and its size-matched non-binding control $Z_{\text {Taq:3638 }}$ were recombinantly fused with a C-terminal selenocysteine-containing Sel-tag ( $Z_{\text {EGFR:2377-ST }}$ and $Z_{\text {Taq:3638 }}$ ST). The proteins were site-specifically labeled with DyLight488 for flow cytometry and ex vivo tissue analyses or with ${ }^{11} \mathrm{C}$ for in vivo PET studies. Kinetic scans with the ${ }^{11} \mathrm{C}$-labeled proteins were performed in healthy mice and in mice bearing xenografts from human FaDu (squamous cell carcinoma) and A431 (epidermoid carcinoma) cell lines. Changes in tracer uptake in A431 xenografts over time were also monitored, followed by ex vivo proximity ligation assays (PLA) of EGFR expressions.

Results: Flow cytometry and ex vivo tissue analyses confirmed EGFR targeting by $Z_{\text {EGFR:2377-ST-DyLight488. }}$

[Methyl ${ }^{1{ }^{11} \mathrm{C}}$-labeled $\mathrm{Z}_{\mathrm{EGFR}: 2377}-\mathrm{ST}-\mathrm{CH}_{3}$ and $\mathrm{Z}_{\text {Taq:3638- }}-\mathrm{ST}_{-}-\mathrm{CH}_{3}$ showed similar distributions in vivo, except for notably higher concentrations of the former in particularly the liver and the blood. [Methyl $\left.{ }^{11}{ }^{1}\right]-Z_{\text {EGFR:2377 }}-\mathrm{ST}_{-} \mathrm{CH}_{3}$ successfully visualized FaDu and A431 xenografts with moderate and high EGFR expression levels, respectively. However, in FaDu tumors, the non-specific uptake was large and sometimes equally large, illustrating the importance of proper controls. In the A431 group observed longitudinally, non-specific uptake remained at same level over the observation period. Specific uptake increased with tumor size, but changes varied widely over time in individual tumors. Total (membranous and cytoplasmic) EGFR in excised sections increased with tumor growth. There was no positive correlation between total EGFR and specific tracer uptake, which, since $Z_{\text {EGFR:2377 }}$ binds extracellularly and is slowly internalized, indicates a discordance between available membranous and total EGFR expression levels.

(Continued on next page)
\end{abstract}

\footnotetext{
* Correspondence: sharon.stone-elander@ki.se

${ }^{\dagger}$ Equal contributors

'Department of Medical Biochemistry and Biophysics, Karolinska Institutet,

Stockholm, Sweden

${ }^{2}$ Department of Clinical Neurosciences, Karolinska Institutet, Stockholm,

Sweden

Full list of author information is available at the end of the article
} 
(Continued from previous page)

Conclusions: Same-day in vivo dual tracer imaging enabled by the Sel-tag technology and ${ }^{11} \mathrm{C}$-labeling provides a method to non-invasively monitor membrane-localized EGFR as well as factors affecting non-specific uptake of the PET ligand.

Keywords: Epidermal growth factor receptor, Affibody molecule, Sel-tag, Dual tracer imaging, Positron emission tomography

\section{Background}

The overexpression of epidermal growth factor receptor (EGFR) in many human tumors [1] has been related to metastasis, therapy resistance, and poor prognosis [2]. Extracellular, intracellular, and mutated EGFRs have been therapeutic targets in cancer for some time [3] and the ability to quantify expression levels could be used to identify patients that would benefit from anti-EGFR therapies. However, poor correlations between conventional assessments of EGFR expression and clinical responses have raised questions about whether it is the assays that are inadequate or whether there are fundamental issues related to the in vivo function of EGFRs that need to be considered [4]. Non-invasive nuclear medicine-based molecular imaging of receptors can potentially offer advantages over conventional biopsy-based analyses since these methods provide global tumor assessments that should be less prone to sampling errors. Radiolabeled tracers ranging from small molecules up to antibodies have been developed for EGFR imaging using single photon and positron emission tomography (SPECT and positron emission tomography (PET), respectively) [5]. However, there is still no consensus on the most appropriate radiotracer to use. Most of the tracers studied have had issues concerning in vivo specificity, selectivity, and/or sensitivity. In addition to variations in non-targeting uptakes due to the varying characteristics of individual tumors in which the receptor modeling is to be performed, the imaging results have also been affected by metabolism, limited bioavailability, and inappropriate kinetics of the imaging probes [6].

Dual or paired tracer imaging has been used in neuroreceptor imaging since the mid-1980s to assess nontargeting contributions to the signal of targeting radiotracers, but to a much less extent for receptor imaging in tumors. Most of the studies pairing tracers in the same tumor have either been performed in SPECT studies in the brain or in preclinical optical imaging of surface tumors [7]. We aimed here to examine some of the issues reported in EGFR imaging by using a dual tracer imaging strategy based on Affibody molecules and preclinical PET. Affibody molecules are small size proteins (58 residues, $\approx 7 \mathrm{kDa}$ ) obtained by randomizing thirteen surface residues in the Affibody protein scaffold [8]. High-affinity binders have been developed and evaluated for SPECT or
PET imaging of tumors [9]. Several probes targeting EGFR have been developed [10, 11]. In particular, $Z_{\text {EGFR:1907 has }}$ been labeled for preclinical SPECT $\left({ }^{111} \mathrm{In}\right)$ and PET $\left({ }^{64} \mathrm{Cu}\right.$, ${ }^{18}$ F) applications [12-14]. Subsequently, $Z_{\text {EGFR:2377, which }}$ binds with equally high (subnanomolar) affinity to human and murine EGFR, was developed so that the tracer behavior in rodents would be more analogous to that expected in humans [15]. $\mathrm{Z}_{\text {EGFR:2377 }}$ was labeled with ${ }^{111} \mathrm{In}$ for SPECT studies, and EGFR-expressing tumors were successfully imaged when the tracer specific activity was appropriately adjusted to reduce competing uptake in non-tumor tissues [16]. Fluorescently labeled targeting and non-targeting Affibody molecules have also recently been co-injected in preclinical fluorescence imaging studies in order to estimate and correct for non-specific contributions to the EGFR expression levels determined with the targeting Affibody molecule [17].

Here, we used small animal PET and short-lived, dual targeting and non-targeting Affibody molecules to examine some of the parameters affecting the in vivo quantification of EGFR receptors. We paired $Z_{\text {EGFR:2377 with a }}$ size-matched control $\mathrm{Z}_{\mathrm{Taq}: 3638}$ (S1-1 in [18]) to perform in vivo studies of binding to EGFR-expressing xenografts. To examine the ability of $\mathrm{Z}_{\mathrm{EGFR}: 2377}$ to detect different EGFR expression levels in tumors with varying characteristics, we used two models (A431 (epidermoid carcinoma) and FaDu (squamous cell carcinoma)) and, in one series, examined changes in tracer uptake with the growth of A431 tumors. Labeling was performed with ${ }^{11} \mathrm{C}\left(t_{1 / 2}=20.4 \mathrm{~min}\right)$. This permitted observation in vivo for $60 \mathrm{~min}$, which is consistent both with the fairly

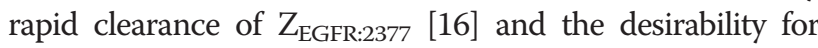
performing "same-day" sequential imaging with the control $\mathrm{Z}_{\text {Taq:3638 }}$ in each individual. A Sel-tag (ST) containing a selenocysteine residue within a C-terminal -Gly-Cys-SecGly sequence [19] was used for the rapid and site-specific labeling with ${ }^{11} \mathrm{C}$, giving the radiotracers [methyl- ${ }^{11} \mathrm{C}$ ]-

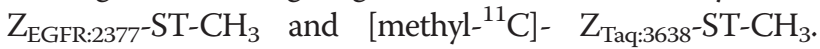
Our results demonstrate the feasibility and potential advantages of same-day in vivo dual tracer imaging of membrane EGFR levels using ${ }^{11} \mathrm{C}$-labeled Affibody molecules and suggest this PET approach to be useful for non-invasively evaluating specific and unspecific retention of labeled probes in peripheral tumors with varying target expressions. 


\section{Results}

Preparation and labeling of the Sel-tagged Affibody molecules

The Sel-tagged Affibody molecules were successfully obtained by expression in $E$. coli as C-terminal fusions to green fluorescent protein (GFP), then recovered with immobilized metal ion affinity chromatography (IMAC), released by tobacco etch virus (TEV)-protease cleavage, and purified by high-performance liquid chromatography (HPLC). Correct expected masses (7.267 and $7.157 \mathrm{kDa}$ for $\mathrm{Z}_{\mathrm{EGFR}: 2377}-\mathrm{ST}$ and $\mathrm{Z}_{\mathrm{Taq}: 3638} \mathrm{ST}$, respectively) were verified by electrospray ionization-mass spectroscopy.

Using the previously developed protocol [20], Affibody molecules were ${ }^{11} \mathrm{C}$-labeled and purified within $50 \mathrm{~min}$, with decay-corrected yields up to $20 \%$ based on used $\left[{ }^{11} \mathrm{C}\right]$ methyl iodide $\left(\mathrm{CH}_{3} \mathrm{I}\right)$. Radiochemical purities were $95 \pm 3 \%$, with labeled dimer occasionally detected. Efforts were not made to increase the specific radioactivity since an optimal rather than the highest possible specific activity was required $[13,14,16]$.

\section{EGFR targeting by $Z_{\text {EGFR:2377 }}-\mathrm{ST}$ but not $\mathrm{Z}_{\text {Taq:3638 }}$-ST}

In vitro and ex vivo assays were used to test whether the C-terminal ST and labeling at the ST interfered with the EGFR binding of $Z_{\text {EGFR:2377 (characterized in [16]). Flow }}$ cytometry (Fig. 1a) showed $\mathrm{Z}_{\text {EGFR:2377-ST-[DyLight488] }}$ (red curves) clearly bound to A431 and less to $\mathrm{FaDu}$, but not at all to MDA-MB-453 cells (human breast carcinoma), which correlated well with EGFR levels (western blot,

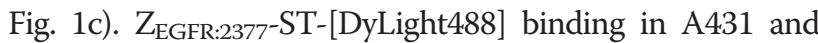

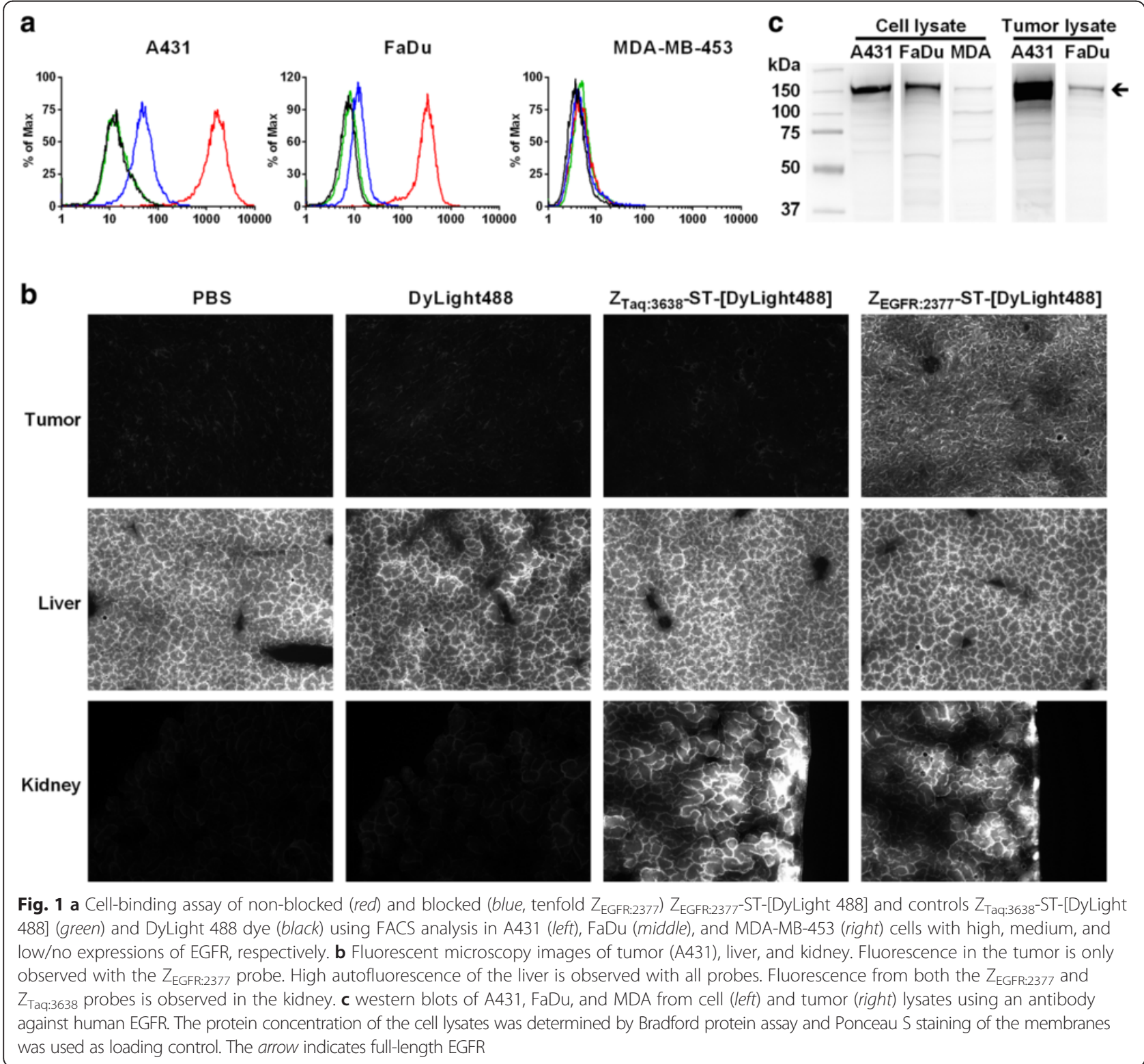


$\mathrm{FaDu}$ cells was significantly reduced by blocking with excess $\mathrm{Z}_{\text {EGFR:2377 }}$ (blue curves). Non-targeting $\mathrm{Z}_{\text {Taq:3638}} \mathrm{ST}$ [DyLight488] (green curves) showed no binding.

In vivo targeting ability was compared by analyzing sections of tissues excised from mice that had been injected with the fluorescently labeled Affibody molecules. Fluorescence in the tumors was only detected with

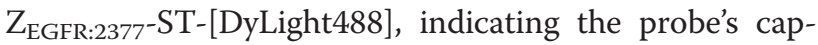
ability for EGFR targeting in vivo (Fig. 1b, top panels). Binding in the liver (Fig. 1b, middle panels) could not be evaluated due to autofluorescence [21]. Fluorescence from both tracers was observed in the kidneys (Fig. 1b, lower panels), in agreement with renal elimination of Affibody molecules [9].

\section{In vivo biodistribution of [methyl- ${ }^{11} \mathrm{C}$ ]-labeled $\mathrm{Z}_{\mathrm{EGFR}: 2377}$ -} $\mathrm{ST}-\mathrm{CH}_{3}$ and $\mathrm{Z}_{\mathrm{Taq}: 3638}-\mathrm{ST}-\mathrm{CH}_{3}$

Key features of the tracers' distributions in healthy mice during $60 \mathrm{~min}$ are shown in Fig. 2. The amount of protein injected was adjusted by spiking with unlabeled protein. Two protein amounts, 27 and $49 \mu \mathrm{g}$, were used in accordance with previous studies $[14,16]$, to demonstrate that the large uptake in the liver could be at least partially blocked so tracer would be available for tumor targeting. EGFR blocking was tolerated well with the Affibody molecules, since they are antagonistic or pharmacologically neutral [16]. Even after the partial blocking, larger uptakes of [methyl- $\left.{ }^{11} \mathrm{C}\right]-\mathrm{Z}_{\mathrm{EGFR}: 2377}-\mathrm{ST}$ $\mathrm{CH}_{3}$ were still observed in the liver (Fig. 2a). The timeactivity curves (TACs) were very similar for the two masses injected, and the standard deviations were similar to those of the non-spiked [methyl- $\left.{ }^{11} \mathrm{C}\right]-\mathrm{Z}_{\text {Taq:3638- }} \mathrm{ST}$ $\mathrm{CH}_{3}$ (Fig. 2b). Therefore, instead of the four individual curves, one curve of the means of the four animals with the standard deviations is shown here. Radioactivity in the arterial and venous blood began to plateau after

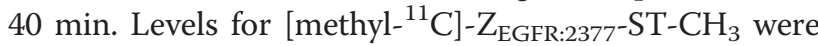
higher than for [methyl- $\left.{ }^{11} \mathrm{C}\right]-\mathrm{Z}_{\mathrm{Taq}}: 3638-\mathrm{ST}-\mathrm{CH}_{3}$. This observation is consistent with the binding of the targeting ligand to shed or soluble EGFR, to smooth muscle cells in the blood vessels and/or tracer dissociating from EGFR receptors and returning to the circulation [16]. The higher uptake for the targeting ligand in the muscle may be due to differences in blood radioactivity since there are no or very low EGFR levels in skeletal muscle and bone marrow.

Liver radioactivity plateaued after $30 \mathrm{~min}$ but was $30 \%$ higher with [methyl $-{ }^{11} \mathrm{C}$ ]- $\mathrm{Z}_{\text {EGFR:2377 }}-\mathrm{ST}-\mathrm{CH}_{3}$, since the hepatic EGFR binding is not completely blocked at these doses [14, 16]. Contributions from blood pool, non-specific uptake, and/or tracer metabolism are revealed by the [methyl- $\left.{ }^{11} \mathrm{C}\right]-\mathrm{Z}_{\mathrm{Taq}} 3638-\mathrm{ST}-\mathrm{CH}_{3}$ uptake. The
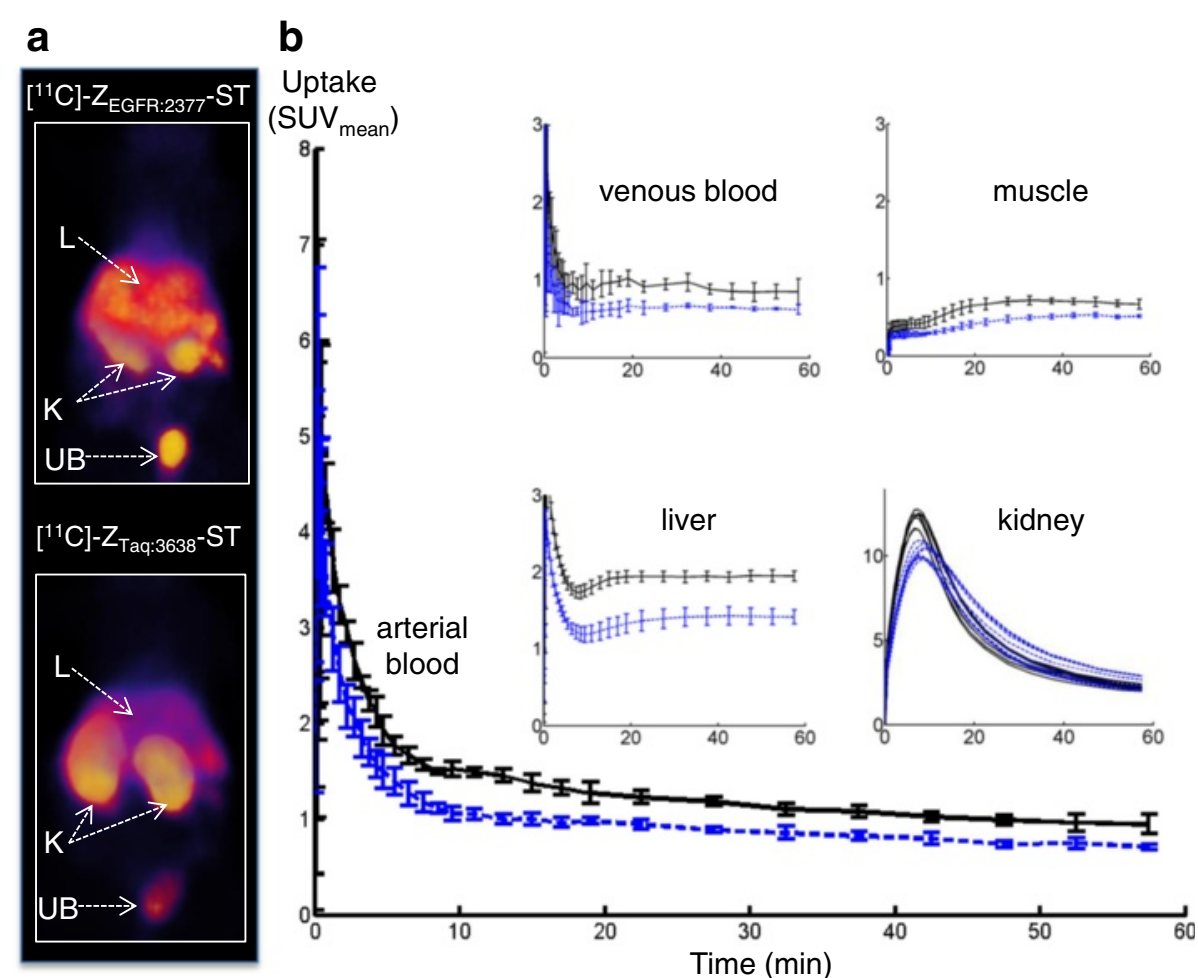

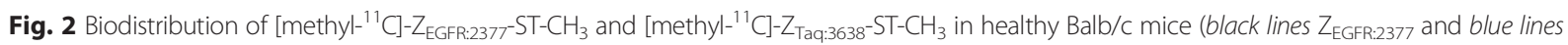

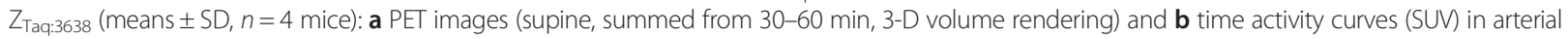
and venous blood, skeletal muscle, liver, and kidney over 60 min after injection 
highest radioactivity concentrations were found in the kidneys and urinary bladder. The higher and slightly earlier peak and a tendency to a faster renal washout observed for [methyl- ${ }^{11} \mathrm{C}$ ]- $\mathrm{Z}_{\mathrm{EGFR}: 2377}-\mathrm{ST}-\mathrm{CH}_{3}$ may be due to the added protein and/or the slightly more positive charge of the control [22]. Low uptakes of radioactivity were measured ex vivo in the lung, pancreas, spleen, stomach, and intestines, but their relative amounts could not be analyzed quantitatively in vivo in the mice due to the influence of partial volume effects (PVEs).

\section{In vivo tumor studies}

Uptakes of [methyl- ${ }^{11} \mathrm{C}$ ]- $\mathrm{Z}_{\text {EGFR:2377- }} \mathrm{ST}-\mathrm{CH}_{3}$ in $\mathrm{FaDu}$ xenografts were generally low (standardized uptake values $\left.(\mathrm{SUV})_{\text {mean }}=0.64-1.22\right)$ and plateaued after $30 \mathrm{~min}$ (Fig. 3a). Uptakes of the control $\left(\mathrm{SUV}_{\text {mean }}=0.68-0.79\right)$ varied from one half to nearly the same levels as that of the targeting protein. Uptake of [methyl- $\left.{ }^{11} \mathrm{C}\right]-\mathrm{Z}_{\mathrm{EGFR}: 2377^{-}}$ $\mathrm{ST}_{-} \mathrm{CH}_{3}$ was heterogeneous in larger $\mathrm{FaDu}$ tumors (Fig. 3b, left side). Even when areas with lower uptake were excluded by thresholding, the $S U V_{\text {mean }}$ for the left and right tumors in this animal only differed by $\approx 15 \%$. Similar results were obtained for one of the other three animals while the larger tumors in the two remaining mice were too necrotic for reasonable comparisons of uptakes between the xenografts. Phosphoimaging (PI) of sections of excised tumors from Fig. 3b confirmed the heterogeneous distribution of the targeting tracer seen in the PET images, in spite of immunohistochemistry (IHC) staining results that indicated fairly homogenous EGFR expressions (Fig. 4a, c vs. d, f). High levels of carbonic anhydrase IX (CAIX) immunostaining (Fig. 4b vs. e) indicated the presence of large hypoxic areas.

In A431 xenografts, uptakes of $\left[\right.$ methyl- $\left.{ }^{11} \mathrm{C}\right]-$ $\mathrm{Z}_{\mathrm{EGFR}: 2377}-\mathrm{ST}-\mathrm{CH}_{3}$ were higher than in FaDu (Fig. 4) $\left(\mathrm{SUV}_{\text {mean }}=0.78-2.49\right)$ while uptakes of the control were usually lower $\left(\mathrm{SUV}_{\text {mean }}=0.22-0.86\right.$; one particular outlier with $\mathrm{SUV}_{\text {mean }}=1.28$ ). In one example (Fig. 5a), the uptake of [methyl- ${ }^{11} \mathrm{C}$ ]- $\mathrm{Z}_{\text {EGFR:2377 }}-\mathrm{ST}-\mathrm{CH}_{3}$ was $\approx 7$ times higher than that of [methyl- $\left.{ }^{11} \mathrm{C}\right]-\mathrm{Z}_{\text {Taq:3638 }}-\mathrm{ST}-\mathrm{CH}_{3}$. The uptake of [methyl- ${ }^{11} \mathrm{C}$ ]- $\mathrm{Z}_{\mathrm{EGFR}: 2377}-\mathrm{ST}-\mathrm{CH}_{3}$ generally increased with the tumor size (Fig. $5 \mathrm{~b}$ ) and appeared to be homogenous in the size range studied here. Interestingly, the SUVs were still increasing at $60 \mathrm{~min}$, indicating that equilibrium was not yet attained, while that of [methyl$\left.{ }^{11} \mathrm{C}\right]-\mathrm{Z}_{\mathrm{Taq}: 3638}-\mathrm{ST}-\mathrm{CH}_{3}$ leveled off from $35 \mathrm{~min}$. Performing acquisitions over more than $60 \mathrm{~min}$ to probe whether the increases eventually leveled off was not possible due to the low counting statistics after three times the half-life of the radionuclide.

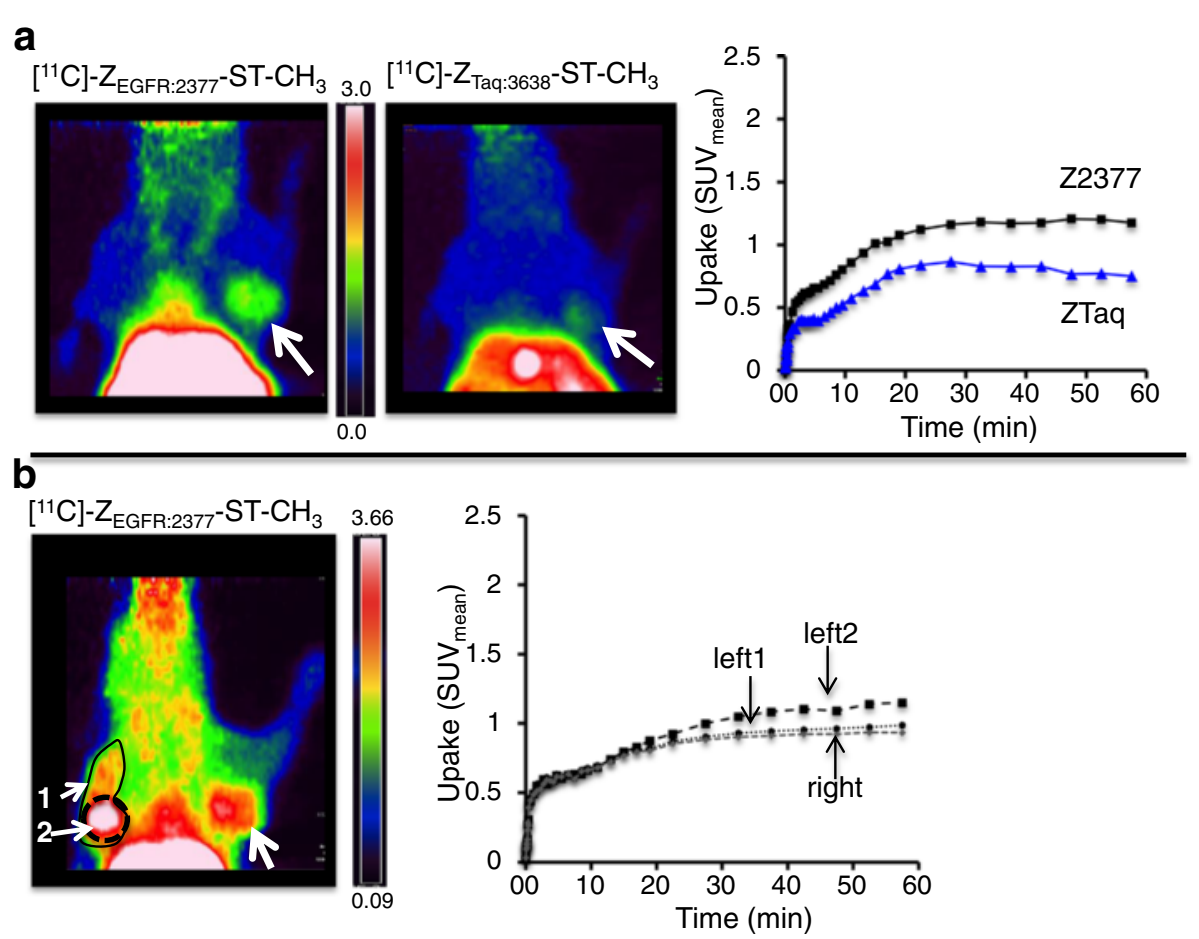

Fig. 3 PET images, summed 30-60 min, and TACs from a SCID mouse (prone) bearing tumors (white arrows): a one FaDu xenograft ( $1 \times 10^{6}$ cells, 12 days) or $\mathbf{b}$ two FaDu xenografts (left: $\left(1 \times 10^{6}\right.$ cells, 12 days); right: $\left(0.5 \times 10^{6}\right.$ cells, 12 days). Comparison A illustrates the higher uptake with targeting [methyl- $\left.{ }^{11} \mathrm{C}\right]-Z_{\text {EGFR:2377- }} \mathrm{ST}-\mathrm{CH}_{3}$ but with a $\approx 60 \%$ non-targeting uptake of [methyl- $\left.{ }^{11} \mathrm{C}\right]-\mathrm{Z}_{\text {Taq:3638 }}-\mathrm{ST}-\mathrm{CH}_{3}$. Comparison B illustrates the visually discernable heterogeneous uptake of the targeting Affibody in the larger tumor on the left. SUV mean is affected by whether the entire (1) or only central ROI (2) of the left tumor is used 
a

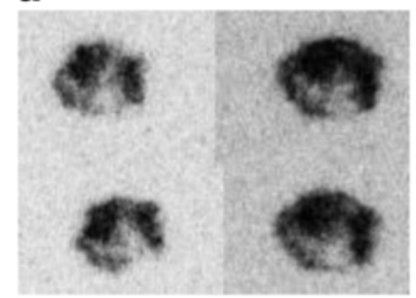

d

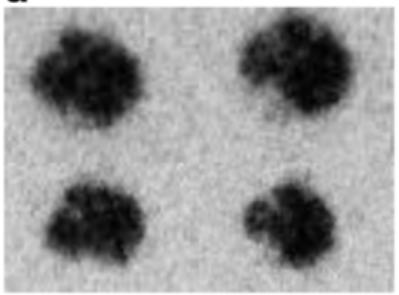

b

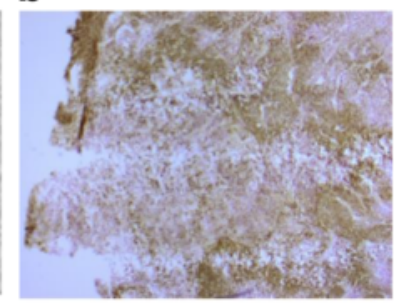

e

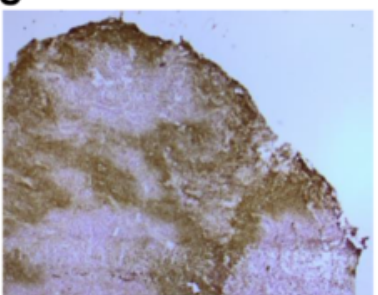

C

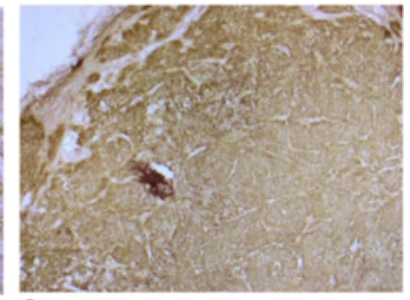

f

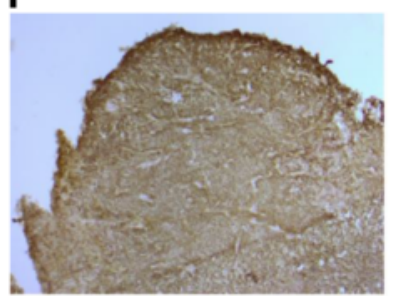

Fig. 4 Ex vivo analyses of sections of the two tumors in Fig. 3b (left tumor (a-c); right tumor $(\mathbf{d}-\mathbf{f})$ ). $\mathbf{a}, \mathbf{d}$ Phosphoimaging of sections of tumors excised immediately after the 60 min PET scan with [methyl- $\left.{ }^{11} \mathrm{C}\right]-Z_{\text {EGFR:2377 }}-\mathrm{ST}_{-} \mathrm{CH}_{3}$. b, e IHC detecting CAIX, staining was performed on formalin-fixed, paraffin-embedded material using antibody against CAIX (BioScience, Slovakia) at a dilution 1:500. $\mathbf{c}, \mathbf{f} ॥$ HC detecting EGFR, staining was performed on formalin-fixed, paraffin-embedded material using antibody against EGFR (Sigma, Sweden) at a dilution 1:800

\section{a}

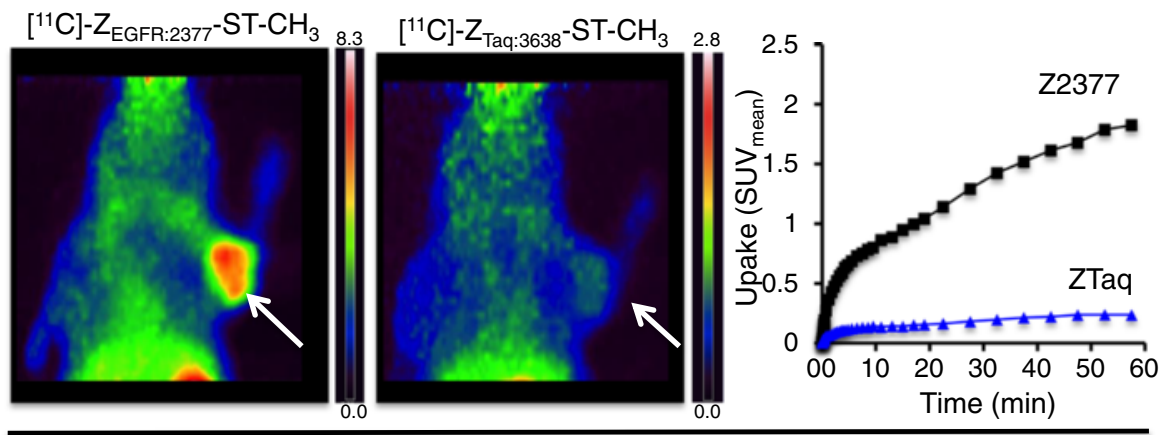

b
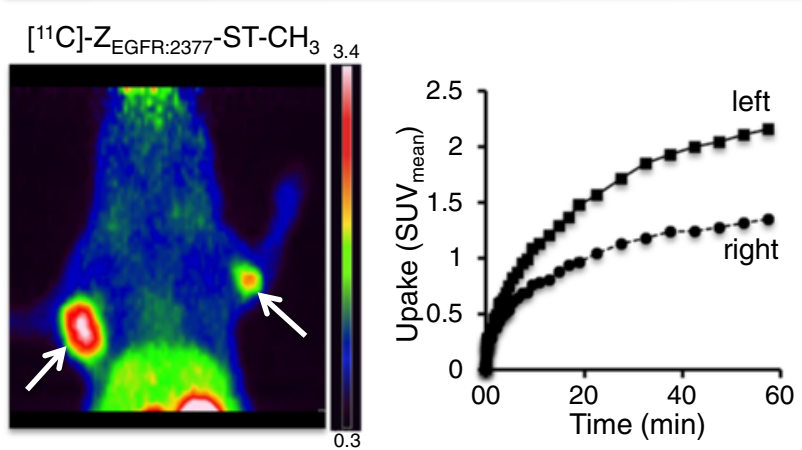

Fig. 5 PET images, summed 30-60 min, and TACs from a Balbc nu/nu mouse (prone) bearing tumors (white arrows): a one A431 xenograft ( $1 \times 10^{7}$ cells, 15 days) or $\mathbf{b}$ two A431 xenografts (left: $1 \times 10^{7}$ cells, 28 days; right: $1 \times 10^{7}$ cells, 25 days). Comparison A shows a 7-times higher uptake with targeting [methyl- ${ }^{11} \mathrm{C}$ - $\mathrm{Z}_{\text {EGFR:2377 }}-\mathrm{ST}-\mathrm{CH}_{3}$ compared to the non-targeting [methyl- $\left.{ }^{11} \mathrm{C}\right]-\mathrm{Z}_{\text {Taq:3638- }} \mathrm{ST}-\mathrm{CH}_{3}$. Comparison B illustrates uptake of the targeting Affibody increasing as the tumors grow from time from inoculation 
In the longitudinal study of ten tumors in five mice (growths as in Fig. 6a), the uptake of $\left[\right.$ methyl- $\left.{ }^{11} \mathrm{C}\right]-$ $\mathrm{Z}_{\mathrm{EGFR}: 2377}-\mathrm{ST}-\mathrm{CH}_{3}$ equilibrated quickly when the tumors were small but was still increasing at $60 \mathrm{~min}$ when the tumors had grown larger (Fig. 6b, blue and green vs. red curves), which suggests that the time of observation needed until maximum uptake can vary with tumor development. The uptake of [methyl- $\left.{ }^{11} \mathrm{C}\right]-\mathrm{Z}_{\mathrm{Taq}: 3638}-\mathrm{ST}-\mathrm{CH}_{3}$ $(0.6 \pm 0.1)$ plateaued and did not, in this series, notably change with tumor size (Fig. 6c). Grouping all scans for the five mice and ten tumors together, the increasing specific uptake (i.e., [SUV $\left.\mathrm{SEGFR:2377}-\mathrm{SUV}_{\mathrm{ZTaq}: 3638}\right]$ ) correlated (exponential regression) with the number of days from the time from inoculation for both $\mathrm{SUV}_{\text {mean }}$ (Fig. 6d, $\left.r^{2}=0.73\right)$ and $\operatorname{SUV}_{\max }\left(r^{2}=0.70\right.$, data not shown). The variance was much greater in the correlations to the xenograft volumes $\left(\mathrm{SUV}_{\text {mean }}\right.$ (Fig. 6e, exponential regression, $r^{2}=0.27$ (the largest tumor was here treated as an outlier and excluded from the plot)) and $\operatorname{SUV}_{\text {max }}\left(r^{2}=0.38\right.$, data not shown)), indicating the correlation to be quite poor. However, several PET studies were performed longitudinally in this study, which took advantage of the strength of in vivo imaging for observing changes on the level of each individual tumor instead of analysing by group that is typical of most ex vivo studies. It was obvious from the monitoring over time that changes in the SUVs were somewhat different for each xenograft. There was a sharp increase in SUVs between the first and second imaging in the very small xenografts, but, as they grew larger, the incremental SUV changes between the second and third experiments were smaller or, in some cases, even decreased (Fig. 6f).

Proximity ligation assay (PLA) analyses of all the sections of six of the harvested tumors showed positive and negative areas with membranous (Fig. 7a, arrows) as well as cytoplasmic (Fig. 7a arrowheads) EGFRs detected. The PLA signals in the tumor sections were generally greater in tumors of larger volumes, but there was quite a large variance and therefore the correlation is considered poor (Fig. $7 b$, linear regression, $r^{2}=0.29$ ). There was, however rather clearly, a negative relation between the PLA signals and the SUVs measured on the final PET imaging day (Fig. 7c, linear regression, $r^{2}=0.74$ ).

\section{Discussion}

This study is, to our knowledge, the first longitudinal in vivo study in tumor xenografts using a radiolabeled EGFRbinding tracer combined with an analogously labeled sizematched control. The short-lived ${ }^{11} \mathrm{C}$ radionuclide enabled same day, paired imaging in each individual tumor. Therefore, the protocol could minimize influences on the results due to changing tumor characteristics over time (compared to when studies are instead performed on same xenograft on different days) or from differing characteristics of different xenografts (when the comparisons are instead performed in different animals). The Sel-tag enabled labeling at the same site with fluorescent and radioactive labels, which allowed evaluations of the tracers' EGFR binding
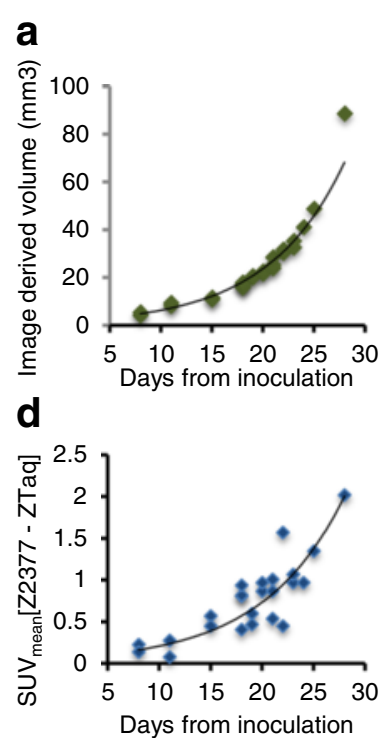

b
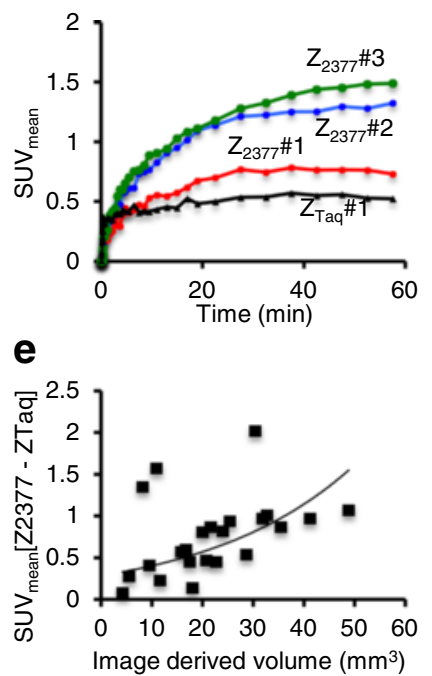

c
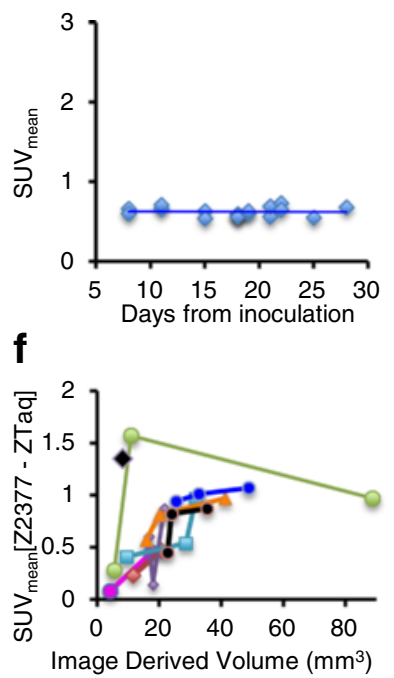

Fig. 6 Data from the longitudinal study of A431 xenografts: a Changes in tumor volumes with the days since inoculation. $\mathbf{b}$ TACs of the differing uptakes in one A431 xenograft of [methyl- $\left.{ }^{11} \mathrm{C}\right]-\mathrm{Z}_{\text {Taq:3638- }}-\mathrm{ST}-\mathrm{CH}_{3}$ (black curve, day 8) and targeting [methyl- $\left.{ }^{11} \mathrm{C}\right]-\mathrm{Z}_{\text {EGFR:2377 }}-\mathrm{ST}-\mathrm{CH}_{3}$ (red, blue, and green curves on days 8,19 , and 21 , respectively). $\mathbf{c ~ S U V}$ mean for the uptake of [methyl- ${ }^{11} \mathrm{C}$ ]- $\mathrm{Z}_{\text {Taq:3638- }}-\mathrm{ST}-\mathrm{CH}_{3}$ measured in the A431 tumors vs. days since inoculation. $\mathbf{d}$ Variations in specific uptake (SUV mean(ZEGFR:2377) $-S U V_{\text {mean(ZTaq:3638) }}$ ) with the growth of all ten xenografts from inoculation. e Variations in specific uptake ( $S U V_{\text {mean }}$ of $Z_{E G F R: 2377}-S U V_{\text {mean }}$ of $Z_{\text {Taq:3638 }}$ ) of all ten xenografts as their volumes increased. $\mathbf{f}$ Variations in specific uptake, SUV mean, in individual xenografts as their volumes increased 

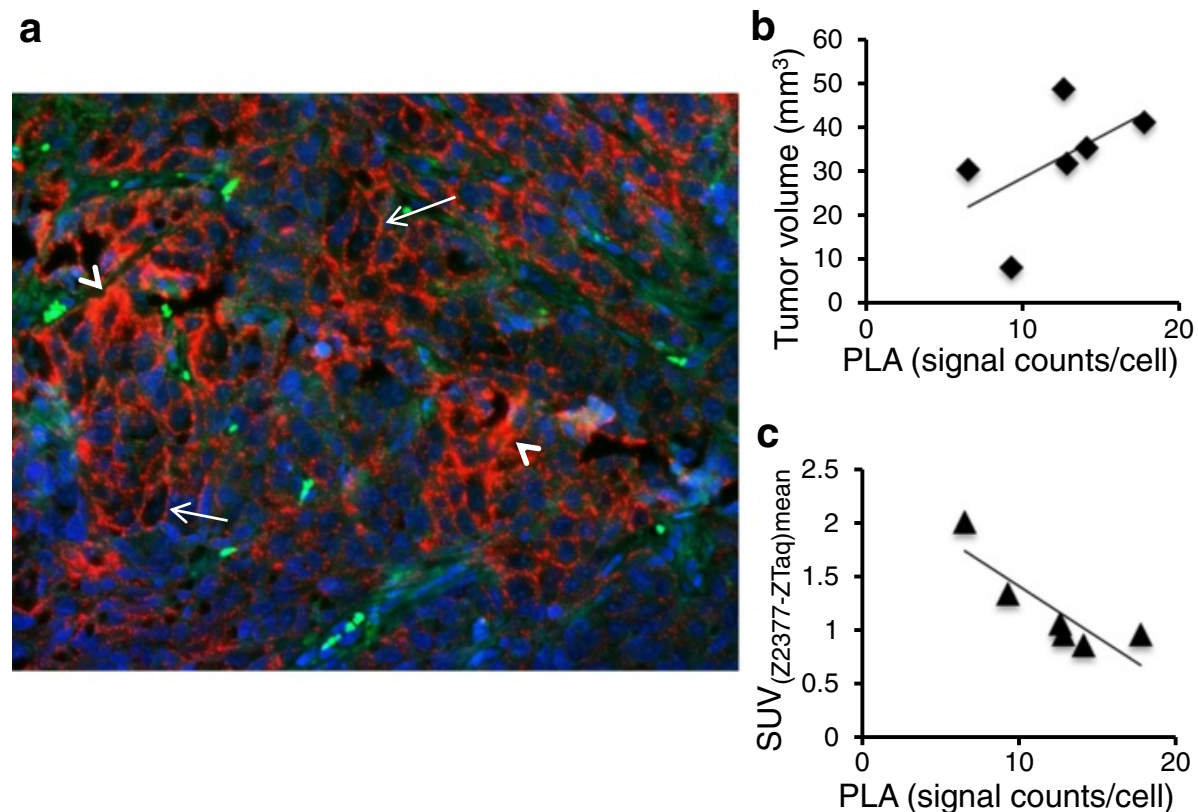

Fig. 7 In situ PLA analyses of EGFR in formalin-fixed, paraffin-embedded sections of A431 xenografts from the longitudinal study. a EGFR-positive tissue, magnification $\times 20$. White arrows and arrowheads indicate membranous and cytoplasmic patterns of EGFR immunostaining, respectively. Red dots: EGFR single proteins, blue: Hoechst nuclear staining, and green: auto fluorescence. b PLA signal counts/cell (relative EGFR expression level) in EGFR positive sections vs. volumes of the excised tumors. c Specific tracer uptake on the last day of imaging vs. the PLA signal counts/ cell in excised tumor sections

capabilities in vitro, ex vivo, and in vivo. Labeling was fast, and yields obtained even with ${ }^{11} \mathrm{C}$ were sufficient for the intended use. $\mathrm{Z}_{\mathrm{EGFR}: 2377}$ had an appropriate affinity and size to quickly distribute from the circulation to the tumor. The results obtained using this dual tracer protocol revealed that the non-specific uptake should be evaluated, especially when receptor levels are low and influences on tracer behavior from other tumor characteristics are comparatively large, and that EGFR levels targeted by a membranebinding radioligand do not directly correlate to the total (extra- plus intracellular) levels.

$Z_{\text {EGFR:2377 }}$ and $Z_{\text {Taq:3638 }}$ were expected to distribute similarly since they are essentially the same size, charges at physiological $\mathrm{pH}$ are nearly neutral and differ only by two (two more lysines in $\mathrm{Z}_{\text {Taq:3638), and they have an }}$ equal number of hydrophobic acids and essentially the same hydropathicity (Affibody $\mathrm{AB}$, personal communication). Differences were, however, observed in their concentrations in blood and several organs in vivo, which were interpreted to be primarily related to $\mathrm{Z}_{\mathrm{EGFR}: 2377}$ binding to peripheral EGFR. If receptor binding is to be quantified with PET, an input function based on either radioactivity in arterial blood or a reference region devoid of receptors is needed [23]. For such studies, it will be important to determine the identity of the radioactivity in the blood. At least part of the $\mathrm{Z}_{\mathrm{EGFR}: 2377}$-related radioactivity in blood delivered to the tumors after 5060 min apparently has EGFR-binding capability, since its uptake, but not that of the control, continued to increase in the larger A431 tumors (Figs. 5 and 6b, c). Blood sampling with subsequent analyses coupled to image-derived blood curves could determine how much of (and when) the radioactivity is intact, free, or bound tracer. These studies are, however, preferably performed in larger animals since the very small blood volumes in mice limit both the sampling frequency and volumes that can be taken for the analyses.

Affibody molecules are $\approx 7 \mathrm{kDa}$ in size. Even though enhanced permeability and retention (EPR) properties of tumors are primarily utilized to enhance delivery of drugs $>40 \mathrm{kDa}$, smaller proteins are also more extravasated in highly vascularized tumors and retained longer due to their impaired lymphatics [24]. The control protein, [methyl- $\left.{ }^{11} \mathrm{C}\right]-\mathrm{Z}_{\mathrm{Taq}: 3638}-\mathrm{ST}-\mathrm{CH}_{3}$, distributed immediately (the vascular input) to both tumors studied here, but additional increases in uptake over $\approx 30 \mathrm{~min}$ (see e.g. Figs. $3 \mathrm{a}$ and $5 \mathrm{~b}$ ) suggest a passive EPR-related retention also of these small proteins during the 1-hr observation period. The non-specific uptake could sometimes be relatively high; it varied between tumor models and was not always the same for xenografts of the same cell line. Both $\mathrm{FaDu}$ and $\mathrm{A} 431$ xenografts are highly angiogenic $[25,26]$, and new blood vessels therefore grow rapidly and eventually become disorganized, dilated, and leaky. There are considerable inter- and intratumoral heterogeneities in the vascular volumes of tumors of different 
angiogenic states [27]. Contributions to tracer behavior from non-specific uptake due to the vascular properties in individual tumors need to be accounted for since they may be quite large and may change over time and during therapy [28]. This was simplest done here (in Fig. $6 \mathrm{~d}-\mathrm{f}$ ) by subtracting the TACs of the non-targeting ligand from that of the targeting to give a measure of the specific uptake. Compartmental modeling can be used to further quantify the binding and non-specific uptakes (e.g., [29, 30] reviewed in [7]). However, TACs from several of these studies (e.g., Figs. 5 and $6 \mathrm{~b}$ ) indicate that the uptake of the targeting tracer did not always reach equilibrium during the 1-hr scan (the limit for the observation time due to the short half-life of ${ }^{11} \mathrm{C}$ ). Mathematical models can be used to quantify irreversibly binding tracers, but they would require an input from arterial plasma [31], which, as discussed above, is far more readily sampled in animals larger than mice. Kinetic analyses of the uptakes of the probe labeled with a longerlived radionuclide might provide additional information about if or when binding equilibrium is achieved. However, in this case, a same-day dual tracer approach to also estimate the non-specific uptake could probably only be done if, for example, the ligands were labeled with different radionuclides and monitored with SPECT.

Other tumor characteristics will also affect quantifications of tracer uptakes. This is illustrated with the $\mathrm{FaDu}$ xenografts imaged here. Here, uptakes of the targeting tracer were low (consistent with low expression levels) but were also visibly intra- and inter-tumorally heterogeneous. The uptake heterogeneity was inconsistent with the fairly homogenous EGFR expressions shown by the ex vivo IHC but could be consistent with the prominent hypoxia levels detected (Fig. 4). Many experimental tumors grow rapidly and quickly become hypoxic. Vessels in hypoxic regions collapse due to increasing pressure in growing tumors. A probe's targeting ability in vivo will thus be affected, since the number of functional vessels delivering the probe has decreased and the distance the probe must penetrate to target the cells has increased [32]. Penetrability is expected to decrease as the size of the probe increases, but these factors affect even the distribution of small $(\leq 0.5 \mathrm{kDa})$ molecules. Although high uptakes of Affibody molecules have been obtained in tumors due to a favorable balance between their high affinity and smaller size compared to antibodies and fragments, [33] hypoxia and collapse of vessels due to increasing pressure would clearly contribute to a disparity between the total receptor levels and those measured by the in vivo imaging tracers.

In the longitudinal A431 study, the uptake of the nontargeting protein did not vary significantly, probably because the tumors were still small and all inoculations were from the same cell culture to minimize variations in initial angiogenic status [34]. On the group level, the specific uptake increased with time from inoculation (Fig. 6d). However, on the individual level, there was a tendency for uptake to level off as sizes increased in several of the tumors (Fig. 6f)). This has previously also been observed with EGFR-targeting 15-kDa nanobodies in larger A431 xenografts and was suggested to be due to necrosis and/or decreasing penetration of the probe [35]. However, the A431 tumors studied here were purposefully kept small, and necrotic areas with heterogeneous tracer uptake were not discernible. According to the PLA analyses, total EGFR levels tended to increase with the size of tumors (Fig. 7b) but did not positively correlate to increases in specific tracer uptake (Fig. 7c). Previous studies have also reported that ex vivo assays of EGFR expressions did not correlate with the in vivo uptake of other targeting ligands (e.g., [36-38]). There are a number of reasons why discrepancies could be expected [4]. For example, ex vivo assays are optimized so maximum binding of the labeled probes can be obtained in the excised sections and are not performed under the same conditions that affect probe accessibility in vivo. Also, they generally only sample a small part of the tumor and are therefore not necessarily representative of the whole tumor. On the other hand, in vivo tracer measurements (like PET) of whole tumor volumes are affected by tracer ability to overcome in vivo pharmacological barriers in order to effectively bind. These techniques also have much lower resolution, so all the details observable with techniques like IHC and PLA are not discernible. The PLA analyses performed here revealed that the EGFRs in the tumors were localized on the membrane as well as in the cytoplasm. $Z_{\text {EGFR:2377 }}$ binds to membranous EGFR and is barely internalized in A431 during at least 5 hrs [16], although the degree of internalization may vary depending on the tumor and time [15]. Since we only monitored the ${ }^{11} \mathrm{C}$-labeled $\mathrm{Z}_{\mathrm{EGFR}: 2377 \text {-based probe during }}$ a 1-hr scan, it was probably primarily binding to available membranous receptors. Therefore, no correlation to the total (membranous and cytoplasmic) expression levels revealed with IHC and PLA techniques should be expected.

Receptors are not static systems. For example, fluxes in the levels of endogenous ligands influence the receptors that are available for binding by radioligands as well as by receptor-targeting pharmaceuticals. Ligand/receptor interactions can lead to changes in the localization of the receptors. Influences of the endogenous ligand on levels of dopamine receptors have been actively studied with PET (e.g., [39]), and this is also an area of active research on other neuroreceptor systems. The dynamics of receptor availability are likewise very important in many aspects of cancer research. EGFR dimerization, internalization, receptor down-regulation, and degradation are all major determinants of the nature and duration of 
the receptor signaling [40]. Differences in the membranous vs. cytoplasmic locations of EGFRs have been suggested to be associated with tumorigenesis and a prognostic factor for overall survival (e.g., [41, 42]). The availability of appropriate in vivo imaging tools could be very valuable for probing these differences in order to better understand factors affecting the dynamics of the receptor cyclisations, similar to studies performed in neuroreceptor PET. Furthermore, many anti-EGFR drugs target the membranous receptor. Therefore, imaging probes that monitor the availability of these targets can be important for making prognoses about who would benefit from these therapeutic strategies. It has been suggested that EGFR status in vivo might be studied in serial biopsies of normal and tumor tissues [4]. We suggest instead that this serial dual Affibody-based tracer imaging technique, possibly in tandem with tracers such as ${ }^{11} \mathrm{C}$-labeled erlotinib [43] that target the EGFR tyrosine kinase domain (and therefore estimate the receptors in both the membrane and cytoplasm), could provide non-invasive methods for studying changes in numbers and locations of receptors during tumor growth and EGFR cycling.

\section{Conclusions}

This study demonstrated the feasibility of using a dual PET tracer strategy using EGFR-targeting [methyl- ${ }^{11} \mathrm{C}$ ]-

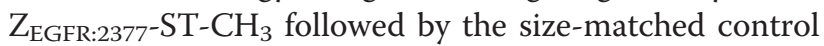
[methyl- ${ }^{11} \mathrm{C}$ ]- $\mathrm{Z}_{\mathrm{Taq}: 3638}-\mathrm{ST}-\mathrm{CH}_{3}$ to study EGFR levels and examine underlying factors contributing to the imaging read-out. Though the specific uptake did differ for tumors with different EGFR expression levels, the uptakes were also affected to different degrees by factors in the tumor architecture limiting their access and non-specific uptake mechanisms, as well as whether the EGFRs to be quantified are localized extra- or intracellularly. This tracer pair appears promising for further applications as investigational imaging biomarkers in PET studies of fluctuations in accessible membrane EGFRs.

\section{Methods}

DNA constructions and expression of Sel-tagged Affibody molecules

The EGFR-binding Affibody molecule $\mathrm{Z}_{\text {EGFR:2377 }}[15,16]$ and the irrelevant $T a q$ polymerase-binding Affibody molecule $\mathrm{Z}_{\text {Taq:3638 }}$ [18] were fused with a C-terminal ST as previously described $[19,44]$. Gene segments encoding a hexahistidyl tag $\left(\mathrm{H}_{6}\right)$, GFP, and a cleavage site for TEV-protease were introduced upstream of the Affibody molecules using polymerase chain reaction (PCR), to encode the constructs $\mathrm{H}_{6}$-GFP-TEV-Z $\mathrm{E}_{\mathrm{EGFR}: 2377}-\mathrm{ST}$ and $\mathrm{H}_{6}$ GFP-TEV-Z $Z_{\text {Taq:3638 }}$ ST. Sequence-confirmed plasmids were transformed to BL21(DE3) cells (Novagen) already harboring the pSUABC plasmid [45]. The two fusion proteins were expressed in shake flasks (LB medium supplemented with $50 \mu \mathrm{g} / \mathrm{mL}$ kanamycin and $34 \mu \mathrm{g} / \mathrm{mL}$ chloramphenicol. Gene expression was induced by adding isopropyl $\beta$-D-1-thiogalactopyranoside to a final concentration of $0.5 \mathrm{mM}$. L-Cysteine and selenite were added to the cultures to a final concentration of $1 \mu \mathrm{M}$ and $5 \mathrm{nM}$, respectively, and cultivations were continued overnight at $25{ }^{\circ} \mathrm{C}$. Cells were harvested by centrifugation at 5,000 rpm and disrupted by sonication followed by centrifugation $16,000 \mathrm{rpm}, 20 \mathrm{~min}, 4{ }^{\circ} \mathrm{C}$. The two fusion proteins were purified by IMAC on a HisTrap FF column (GE Healthcare) and eluted with $50 \%$ tris(hydroxymethyl)aminomethane hydrochloride (Tris)-HCl buffer, $50 \mathrm{mM}, \mathrm{pH} 8.0$, containing $500 \mathrm{mM}$ imidazole. Buffer was exchanged to TEV cleavage buffer $(50 \mathrm{mM}$ Tris- $\mathrm{HCl} \mathrm{pH}$ 8, $0.5 \mathrm{M}$ ethylenediaminetetraacetic acid (EDTA), $1 \mathrm{mM}$ dithiothreitol (DTT)) by dialysis prior to digestion by TEV protease overnight at $4{ }^{\circ} \mathrm{C}$ using 50 times excess of a His-tagged TEV protease. Cleavage mixtures were applied on IMAC columns, and Affibody molecules were recovered in the flow-through. Protein purity was assessed by SDS-PAGE analysis. $Z_{\mathrm{EGFR}: 2377^{-}}$ $\mathrm{ST}$ and $\mathrm{Z}_{\mathrm{Taq}: 3638} \mathrm{ST}$ were further purified by reversed phase chromatography using a Resource RPC 1-ml column (GE Healthcare), using the following buffer system: buffer A, $0.1 \%$ trifluoroacetic acid (TFA) in water, and buffer B, $0.1 \%$ TFA in acetonitrile. The protein was eluted with a gradient of $5-50 \%$ buffer B over $20 \mathrm{~min}$.

\section{Fluorescence labeling to produce $\mathrm{Z}_{\mathrm{EGFR}: 2377}$-ST- and $\mathrm{Z}_{\text {Taq:3638-ST-[DyLight488] }}$}

$\mathrm{Z}_{\mathrm{EGFR}: 2377}-\mathrm{ST}$ and $\mathrm{Z}_{\mathrm{Taq}: 3638}-\mathrm{ST}$ were labeled specifically at the Sec residue using maleimide-activated DyLight 488 (Pierce). Briefly, Sel-tagged Affibody $(30 \mu \mathrm{M})$ was reduced with DTT $(1 \mathrm{mM})$ at room temperature for $30 \mathrm{~min}$ and then incubated in the dark with DyLight 488 (2.5 $\mathrm{mM}$, dimethylsulfoxide (DMSO)) for $30 \mathrm{~min}$. DTT (5 $\mathrm{mM})$ was added to quench the reaction, and the Affibody-ST-[DyLight488] was purified and desalted to physiologically buffered saline (PBS) through a NAP-5 column (GE Healthcare). The concentration of the

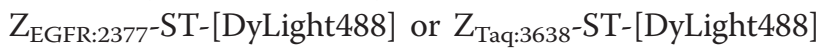
was determined spectrophotometrically using an extinction coefficient of $21,050 \mathrm{M}^{-1} \mathrm{~cm}^{-1}$ at $280 \mathrm{~nm}$ by a Nanodrop (Thermo). The labeled proteins were stored in the refrigerator without direct exposure to light.

\section{${ }^{11} \mathrm{C}$-Labeling to produce [methyl- ${ }^{11} \mathrm{C}$ ]- $\mathrm{Z}_{\text {EGFR:2377 }}-\mathrm{ST}-\mathrm{CH}_{3}$ and $-\mathrm{Z}_{\text {Taq:3638 }}-\mathrm{ST}-\mathrm{CH}_{3}$}

The Sel-tagged Affibody molecules were ${ }^{11} \mathrm{C}$-labeled specifically at the Sec residue, by the method used previously $[19,20,29,46]$. Briefly, the Sel-tagged Affibody molecule was reduced with DTT $(1 \mathrm{mM})$ at $35-37{ }^{\circ} \mathrm{C}$ for $\geq 20$ min. An aliquot $(10-25 \mu \mathrm{l})$ of $\left[{ }^{11} \mathrm{C}^{-C} \mathrm{H}_{3}\right.$ 
(prepared as in [47] from cyclotron-produced $\left[{ }^{11} \mathrm{C}^{1} \mathrm{CO}_{2}\right.$ (PETtrace, GE Healthcare)) and trapped in DMSO $(0.2 \mathrm{ml}))$ was added. After $20 \mathrm{~min}$ at $35-37^{\circ} \mathrm{C}$, the reaction was quenched with DTT (5 mM) and the [methyl$\left.{ }^{11} \mathrm{C}\right]$-Affibody-ST- $\mathrm{CH}_{3}$ was desalted (NAP-5, PBS). Radiochemical purity was analyzed by radio-HPLC (Superdex Peptide 10/300 GL (GE Healthcare) and eluted with PBS, using ultraviolet- $(210 \mathrm{~nm})$ and radiodetectors in series).

\section{Cell lines and animals}

All cell lines were purchased from American Type Culture Collection and cultured at $37{ }^{\circ} \mathrm{C}$, supplemented with $5 \% \mathrm{CO}_{2}$ in a humidified environment. A431 and FaDucells were cultured in Dulbecco's Modified Eagle's Medium (DMEM) $(4500 \mathrm{mg} / \mathrm{L}$ D-glucose containing Lglutamine) whereas MDA-MB-453 was cultured in DMEM (1000 mg/L D-glucose containing L-glutamine). All media were additionally supplemented with $1 \mathrm{mM}$ sodium pyruvate, 100 units penicillin $/ \mathrm{mL}, 100 \mu \mathrm{g}$ streptomycin $/ \mathrm{mL}$, and $10 \%$ foetal bovine serum. Media for FaDu cells were further supplemented with $0.1 \mathrm{mM}$ non-essential amino acids and 2 mM HEPES. EGFR expression levels were confirmed using western blotting (Fig. 1c). The integrity of the cell lines was verified with short tandem repeat (STR) profiling cell authentication analysis (LGC Standards).

Balb/c, SCID, and Balb/c (nu/nu) mice were purchased from Charles River. The animals were housed under standard conditions according to local regulations, with access to food and water ad libitum in the Department of Comparative Medicine at Karolinska University Hospital, Solna.

\section{Cell-binding assay using fluorescence-activated cell sorting (FACS) analysis}

Cells were trypsinized, washed with PBS containing $1 \%$ albumin, divided into $200 \mu \mathrm{l}$ aliquots containing 300,000 cells, which were then incubated $1 \mathrm{~h}$ with $0.1 \mu \mathrm{M}$ of either

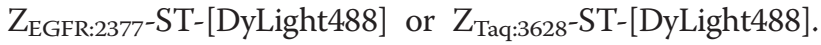
The labeled cells were subsequently separated from nonbound tracer by centrifugation. PBS buffer was used as a negative control. For blocking experiments, cells were pre-incubated with $1 \mu \mathrm{M}$ non-labelled $\mathrm{Z}_{\mathrm{EGFR}: 2377} \mathrm{ST}$ for 5 min before adding $0.1 \mu \mathrm{M} \mathrm{Z}_{\mathrm{EGFR}: 2377}$-ST-[DyLight488]. After shaking for $1 \mathrm{~h}$ at room temperature, the cells were washed with PBS containing $1 \%$ albumin, suspended in PBS and then analysed with a FACSort Calibur flow cytometer (Becton Dickinson).

\section{Ex vivo fluorescent imaging of liver, kidney, and xenograft sections}

A431 cells $\left(10^{7}\right.$ in $0.15 \mathrm{ml}$ PBS) were inoculated subcutaneously (s.c.) into the right flank of four mice (Balb/c, nu/nu, female, $18-20 \mathrm{~g}, 10$ weeks old). After 3 weeks, the mice were injected intravenously (i.v.), in the tail vein with either PBS, $60 \mu \mathrm{M}$ Dylight 488 dye, $60 \mu \mathrm{M}$ $\mathrm{Z}_{\text {EGFR:2377-ST-[DyLight488], }}$ or $60 \mu \mathrm{M} \quad \mathrm{Z}_{\text {Taq:3638-ST- }}$ [DyLight 488] $(0.2 \mathrm{ml})$. Mice were sacrificed 1-h postinjection (p.i.), and tissues were excised, snap frozen $\left(-78{ }^{\circ} \mathrm{C}\right)$, and sectioned $(25 \mu \mathrm{m})$ using a freezing microtome. The fluorescence was documented using an Axio Observer.Z1 fluorescence microscope (Zeiss).

\section{Western blotting}

Western blotting was performed using fresh cell lysates or snap frozen tumor tissue excised from the animal. Briefly, cells or tumor was first homogenized with lysis buffer (50 mM Tris-HCl, pH 7.5, 5 mM EDTA, $150 \mathrm{mM}$ $\mathrm{NaCl}, 1 \%$ Triton X-100) in the presence of protease inhibitor, and then three cycles of freeze-thawing were applied on the mixture. The insoluble components including cell or tissue debris were removed by centrifugation. The supernatant corresponding to $20 \mu \mathrm{g}$ of total protein was analyzed by western blotting (Life technology) using an antibody against human EGFR (Santa Cruz, sc-03, 1:200). The reaction product was detected by enhanced chemiluminescence (Perkin Elmer).

\section{Immunohistochemistry}

Tissues were resected, fixed in $2 \%$ buffered formaldehyde, dehydrated, embedded in paraffin, and sectioned. The sections were then deparaffinized with xylene, rehydrated, and microwaved and then incubated overnight with the monoclonal primary antibodies diluted in $1 \%$ (wt/vol) BSA and visualized by standard avidin-biotin-peroxidase complex technique (Vector Laboratories, Burlingame, CA, USA). Counterstaining was performed with Mayer's hematoxylin. The antibody against EGFR (Sigma, Sweden) was used at a dilution 1:800, and the antibody against CAIX (BioScience, Slovakia) was used at 1:500.

\section{Phosphoimaging}

After the mice were sacrificed, tumors were removed and immediately frozen in dry ice and sectioned using a cryomicrotome (CM 3050S, Leica Microsystems, Wetzlar, Germany) with a thickness of $25 \mu \mathrm{m}$. The sections were exposed on phosphor imaging plates for at least 1 hour. Scanning was performed using a Typhoon FLA 7000 (GE Healthcare).

\section{Proximity ligation assays}

The PLA protocol [48-50] is the standard procedure by which the in situ PLA assay is performed at the proteomics facility, Uppsala, Sweden (http://www.scilifelab.se/ facilities/pla-proteomics) and was followed according to manufacturers' instructions (Olink Bioscience, Uppsala, Sweden). Briefly, formalin-fixed paraffin-embedded tumor 
tissue sections $(4 \mu \mathrm{m})$ were deparaffinised, and the antigen retrieval procedure was performed according to protocol using 1xTarget retrieval solution citrate $\mathrm{pH} 6$ (Dako art, S2369). After blocking, tumor sections were incubated over night $\left(4{ }^{\circ} \mathrm{C}\right)$ with primary antibodies EGFR (D38B1) XP Rabbit mAb \#4267 (Cell Signalling) and mouse monoclonal EGFR (E3138, Sigma-Aldrich), diluted 1:800 with Duolink diluent solution (Sigma-Aldrich). After incubation, the slides were washed in TBS-T, $2 \times 5 \mathrm{~min}$.

PLA secondary probes anti-rabbit MINUS and antimouse PLUS (Duolink kit, Sigma), containing the secondary antibodies conjugated with oligonucleotides, were diluted 1:5 in Duolink antibody diluent. The secondary probe mixture $(40 \mu \mathrm{l})$ was added to each sample, and the slides were incubated in a humidity chamber for $1 \mathrm{~h}$ at $37^{\circ} \mathrm{C}$. The slides were washed in TBS-T, $2 \times 5 \mathrm{~min}$. Following the protocol, the ligation solution was added to each sample, and the slides were incubated for $30 \mathrm{~min}$ at $37^{\circ} \mathrm{C}$. After incubation, the ligation solution was tapped off, the slides were washed in TBS-T, and $40 \mu \mathrm{l}$ of amplification solution was added to each sample followed by incubation for $100 \mathrm{~min}$ at $37{ }^{\circ} \mathrm{C}$. Hoechst 33342 dye nuclear staining (Life Technologies, H1399) was added and incubated for $1 \mathrm{~h}$ at room temperature. After washing in MQ water over night, $15 \mu \mathrm{l}$ of SlowFade Gold Antifade Reagent (Invirogen, S36936) was added to each sample and covered with a cover slip. The positive PLA signals were visualized as distinct red dots in epifluorescence microscope Axioplan 2 (Zeiss). Stacked TIFF images were acquired using Axiovision 4.8. Data analysis for in situ PLA images was performed using the freeware Cell Profiler, developed by the Broad Institute (http://www.cellprofiler.org). The data is given in PLA signals/cell. For PLA signal quantification, three images were taken of each section at $\times 20$ magnification, one each of positive (with high density of fluorescence signals), one of the border between positive and negative tissues, and one of negative tissue (with low concentration of fluorescence signals). The number of PLA signals per image per single cell was estimated as a ratio between total fluorescence signal and total number of cells. At less than two PLA signals per single cell, tissues were counted as a negative.

\section{PET data collection and processing}

PET imaging was performed using a microPET Focus 120 scanner (CTI Concorde Microsystems, Knoxville, TN, USA). List mode data, collected continuously over $60 \mathrm{~min}$ from the tracer injection, were reconstructed using Ordered Subset Estimation Maximum in 2 dimensions (OSEM2D) to increase the spatial resolution, with a picture size of $256 \times 256$ pixels, four iterations, and 16 subsets. Data, normalized and corrected for randoms, dead time, and radioactivity decay, were processed using MicroPET Manager and evaluated using the Inveon Research Workplace (IRW) software (Siemens Medical Systems, Malvern, PA, USA). Venous and arterial ROIs were delineated on the vena cava and left ventricle of the heart, respectively, in the first frames of the scan. Muscle ROIs were drawn on the right hamstring muscle (images summed 0-60 min). ROIs of same shape and size were drawn on the renal cortex and liver, on images summed over periods of maximum uptake after the initial distribution, 10-20 min p.i. Tumor ROIs were delineated on images summed between 30 and $60 \mathrm{~min}$ and thresholded $\approx 75 \%$, based on palpation and subsequent post-mortem measurements. The IRW software calculated the $S U V_{\text {mean }}$ and $S U V_{\text {max }}$ and their standard deviations, along with the volumes of the ROIs (here called the "image-derived volumes," as opposed to those based on measurements by palpations).

\section{PET imaging of [methyl- $\left.{ }^{11} \mathrm{C}\right]-\mathrm{Z}_{\mathrm{EGFR}: 2377}-\mathrm{ST}-\mathrm{CH}_{3}$ and $-\mathrm{Z}_{\mathrm{Taq}: 3638}-\mathrm{ST}-\mathrm{CH}_{3}$}

All experiments involving animals were conducted in accordance with the regulations of the Karolinska Institutet and approved by the local laboratory animal ethics committee (N325/09, N85/11, N416/12). Mice were anesthetized (1.5\% isoflurane (Virbac) blended with air (7:3) in a vaporizer (E-Z systems) delivered through a Microflex non-rebreather mask (Euthanex Corp)) and intravenously (i.v.) injected (tail vein) with [methyl ${ }^{11} \mathrm{C}$ ]-Affibody-ST- $\mathrm{CH}_{3}$. Radioactivity in regions of interest (ROIs) was calculated as mean and maximum standardized uptake values $\left(\mathrm{SUV}_{\text {mean }}\right.$ and $\left.\mathrm{SUV}_{\max }\right)$ normalized to body weight [51]. The uptake of the non-targeting ligand was subtracted from that of the targeting ligand as a measure of specific uptake in some of the analyses.

For the biodistribution studies, Balb/c mice (female, 18$20 \mathrm{~g})$ were i.v. injected with [methyl $\left.{ }^{11} \mathrm{C}\right]-\mathrm{Z}_{\mathrm{EGFR}: 2377}-\mathrm{ST}$ $\mathrm{CH}_{3}$ or $\left[\right.$ methyl ${ }^{11} \mathrm{C}$ ]- $\mathrm{Z}_{\text {Taq:3638 }}-\mathrm{ST}-\mathrm{CH}_{3}$ (volume $\leq 0.2 \mathrm{ml}$ ). Following previous studies on the effects of the administering masses in the interval of $0.1-150 \mu \mathrm{g}$ [16], the masses of the $Z_{\mathrm{EGFR}: 2377}$-based ligand were adjusted or spiked with unlabeled $Z_{\mathrm{EGFR}: 2377}$ to lower the specific activity (here a total mass of 27 or $49 \mu \mathrm{g},(n=2$ each)). The

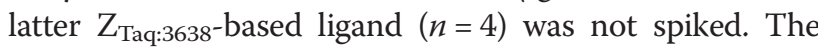
necessity for adjusting the targeting protein mass to reduce non-tumor uptake so tumors could be visualized was confirmed in two FaDu-bearing mice (Additional file 1: Figure S1). Thereafter, for studies in the tumor-bearing mice, the protein in the radiolabeling vial was adjusted so the mass of targeting tracer injected would be 50-100 $\mu$ g, in accordance with the recommended dose interval previously established in [16]. 
In the first pilot studies, mice with single and double inoculations of $\mathrm{FaDu}$ and $\mathrm{A} 431$ cells were studied. Imaging was performed with both the targeting and non-targeting tracer, except in the doubly inoculated $\mathrm{FaDu}$-bearing mice. In those mice, only investigations with [methyl $\left.{ }^{11} \mathrm{C}\right]-\mathrm{Z}_{\mathrm{EGFR}: 2377}-\mathrm{ST}-\mathrm{CH}_{3}$ were performed to see if the uptakes would follow the growth of the tumors. When this was found to not to be the case, only the A431 tumors were chosen for the longitudinal study.

For the study of tumors with low/intermediate EGFR expression, $\mathrm{FaDu}$ cells were injected subcutaneously (s.c.) in SCID mice (male, 18-29 g, single inoculations, $n=4$ mice, with $1 \times 10^{6}$ cells; double inoculations, $n=4$ mice, with $1 \times 10^{6}$ and $0.5 \times 10^{6}$ cells on the left and right shoulders, respectively). FaDu xenografts grow very rapidly once they have established, and for this reason, the sizes of the xenografts were varied by performing the double inoculations on the same day, but with different numbers of cells. After 12-13 days, PET imaging was performed with [methyl- ${ }^{11} \mathrm{C}$ ] $-\mathrm{Z}_{\mathrm{EGFR}: 2377}-\mathrm{ST}-\mathrm{CH}_{3}$ and, for mice with single xenografts, $\geq 3.5$ h later with [methyl$\left.{ }^{11} \mathrm{C}\right]-\mathrm{Z}_{\mathrm{Taq}: 3638}-\mathrm{ST}-\mathrm{CH}_{3}$. The time interval between the two investigations was chosen in order to allow sufficient time ( $\geq 8$ half-lives) for the decay of the radioactivity from the previous investigation. Tumors excised after sacrifice were prepared for analyses by PI and IHC.

A431 cells (high EGFR expression) were injected s.c. in Balb/c, nu/nu mice (female, 16-24 g, single inoculation in four mice, $10^{7}$ cells; two inoculations in five mice, 3 days apart to allow the mice to recover between inoculations, first on the left and then on the right shoulder, $10^{7}$ cells each time). A431 xenografts grow more slowly than $\mathrm{FaDu}$, and therefore, tumors at different stages of development could be observed by spreading out the interval between the first and second inoculations. PET imaging was

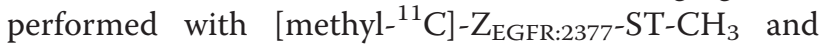
$\geq 3.5 \mathrm{~h}$ later [methyl ${ }^{11} \mathrm{C}$ ] $-\mathrm{Z}_{\mathrm{Taq}: 3638}-\mathrm{ST}-\mathrm{CH}_{3}$. Scanning started from when the xenografts were palpable ( $\geq 8$ days) and thereafter, in the longitudinal study, 211 days between the scanning sessions, depending on xenograft development. Restricted by logistics and the scans allowed by the ethical permission, two to five scans/animal were performed. Details are given in the Additional file 2: Table S1. Excised tumors were subsequently prepared for analyses by PI, IHC, and/or PLA.

\section{Statistics}

Imaging results are presented as values $\pm S D$, if not otherwise specified. Deviations of the measured values from fitted lines were estimated using the Pearson's correlation coefficient, $r^{2}$, ranging from $0-1$, where 1 is a total positive and 0 is no correlation between the variables $X$ and $Y$.

\section{Additional files}

Additional file 1: Figure S1. PET image, summed 40-60 min, of the uptake of targeting [methyl-11C]-ZEGFR:2377-ST-CH3 in one SCID mouse (prone) bearing one s.c. FaDu tumor $(1 \times 106$ cells, 13 days). Only $16-\mu \mathrm{g}$ protein was injected and nearly all radioactivity localized very quickly in the liver giving SUV mean $>2.5$ times larger than for animals receiving spiked tracer injections. The tumor (white arrow) was barely discernible with a faint vascular signal. Even radioactivity distributing to the kidneys and urinary bladder during the 60 min was markedly reduced. Thereafter, the amount of protein administered was adjusted to $50-100 \mathrm{mg}$ to partially block the hepatic uptake and free the ligand for tumor targeting, as discussed in the text. (PPTX $422 \mathrm{~kb}$ )

Additional file 2: Table S2. Imaging information and growth details of the A431 tumors included in the longitudinal study. (DOCX 17 kb)

\section{Abbreviations}

CAIX, carbonic anhydrase IX; Da, Dalton; DMEM, Dulbecco's Modified Eagle's Medium; DMSO, dimethylsulfoxide; DTT, dithiothreitol; EDTA,

ethylenediaminetetraacetic; EGFR, epidermal growth factor receptor; EPR, enhanced permeability and retention; FACS, fluorescence-activated cell sorting; GFP, green fluorescent protein; HPLC, high-performance liquid tomography; i.v., intravenous; IHC, immunohistochemistry; PBS, physiologically buffered saline; PCR, polymerase chain reaction; PET, positron emission tomography; PI, phosphoimaging; PLA, proximity ligand assay; PVE, partial volume effect; S.C., subcutaneous; SCID, severe combined immunodeficiency; SD, standard deviation; Sel, selenocysteine; SPECT, single photon emission computed tomography; ST, sel-tag; SUV, standardized uptake value; TAC, time activity curve; TEV, tobacco etch virus; TFA, trifluoroacetic acid

\section{Acknowledgements}

The authors thank the SciLifeLab PLA Proteomics Facility, Uppsala, Sweden for the PLA analyses; Vladimir Tolmachev and Anna Orlova for their fruitful discussions; Daniel Rosik for his technical assistance; and Hanna Lindberg, Filippa Fleetwood, Dr. John Löfblom, Padraig D'Arcy, and Prof. Sten Nilsson for their input and discussions.

\section{Funding}

This work was supported by grants from the Swedish Foundation for Strategic Research (grant number RBa08-0067); Governmental Agency for Innovation Systems (grant number 2009-00179); the Swedish Cancer Society (grant numbers CAN 2009/739, 2012/341, 2013/586); the Swedish Research Council (grant numbers 40510402, 2004-5104, 2008-2654, 2008-3186, 20142603); Karolinska University Hospital; and Karolinska Institutet.

\section{Authors' contributions}

HW, SS, EA, SL, and SSE conceived the study and participated in its design. HSA coordinated and collected all the underlying information related to the PET studies included. Experimental work (including radiolabeling, development of animal models, in vivo studies, in vitro, and ex vivo analyses) and drafting its description were performed by QC, HW, LL, JOT, MHO, KJ, TT, HSA, and SSE. PET data analyses were performed by JG with participation by HSA and SSE. SS, JG, and SSE drafted the manuscript. All authors read and approved the final manuscript.

\section{Competing interests}

$\mathrm{SS}$ is a member of the technical advisory board of Affibody AB. The authors declare that they have no competing interests.

\section{Author details}

${ }^{1}$ Department of Medical Biochemistry and Biophysics, Karolinska Institutet, Stockholm, Sweden. ${ }^{2}$ Department of Clinical Neurosciences, Karolinska Institutet, Stockholm, Sweden. ${ }^{3}$ Karolinska Experimental Research and Imaging Center, Department of Comparative Medicine, Karolinska University Hospital, Stockholm, Sweden. ${ }^{4}$ Neuroradiology Department, R3:00, Karolinska University Hospital, SE-17176 Stockholm, Sweden. ${ }^{5}$ Department of Oncology and Pathology, Karolinska Institutet, Stockholm, Sweden. ${ }^{6}$ Division of Protein Technology, School of Biotechnology, Royal Institute of Technology, Stockholm, Sweden. 


\section{Received: 19 April 2016 Accepted: 28 June 2016} Published online: 07 July 2016

\section{References}

1. Salomon DS, Brandt R, Ciardiello F, Normanno N. Epidermal growth factorrelated peptides and their receptors in human malignancies. Crit Rev Oncol Hematol. 1995;19:183-232.

2. Nicholson RI, Gee JM, Harper ME. EGFR and cancer prognosis. Eur J Cancer. 2001;37 Suppl 4:S9-15.

3. Nedergaard MK, Hedegaard CJ, Poulsen HS. Targeting the epidermal growth factor receptor in solid tumor malignancies. BioDrugs. 2012;26:83-99.

4. Gusterson BA, Hunter KD. Should we be surprised at the paucity of response to EGFR inhibitors? Lancet Oncol. 2009:10:522-7.

5. Corcoran EB, Hanson RN. Imaging EGFR and HER2 by PET and SPECT: a review. Med Res Rev. 2014;34:596-643.

6. Pantaleo MA, Nannini M, Maleddu A, Fanti S, Nanni C, Boschi S, et al. Experimental results and related clinical implications of PET detection of epidermal growth factor receptor (EGFr) in cancer. Ann Oncol. 2009;20:213-26.

7. Tichauer KM, Wang Y, Pongue BW, Liu JTC. Quantitative in vivo cellsurface receptor modeling in oncology: kinetic modeling and pairedagent principles from nuclear medicine and optical imaging. Phys Med Biol. 2015;60:R239-69.

8. Nord K, Gunneriusson E, Ringdahl J, Ståhl S, Uhlén M, Nygren PÅ. Binding proteins selected from combinatorial libraries of an a-helical bacterial receptor domain. Nat Biotechnol. 1997:15:772-7.

9. Löfblom J, Feldwisch J, Tolmachev V, Carlsson J, Ståhl S, Frejd FY. Affibody molecules: engineered proteins for therapeutic, diagnostic and biotechnological applications. FEBS Lett. 2010;584:2670-80.

10. Friedman $M$, Nordberg $E$, Höidén-Guthenberg I, Brismar H, Adams GP, Nilsson FY, et al. Phage display selection of Affibody molecules binding to the extracellular domain of the epidermal growth factor receptor. Protein Eng Des Sel. 2007;20:189-99.

11. Friedman M, Orlova A, Johansson E, Eriksson TL, Höidén-Guthenberg I, Tolmachev $V$, et al. Directed evolution to low nanomolar affinity of a tumortargeting epidermal growth factor receptor-binding Affibody molecule. J Mol Biol. 2008:376:1388-402.

12. Tolmachev V, Friedman M, Sandström M, Eriksson TL, Rosik D, Hodik M, et al. Affibody molecules for epidermal growth factor receptor targeting in vivo: aspects of dimerization and labeling chemistry. J Nucl Med. 2009:50:274-83.

13. Miao Z, Ren G, Liu H, Jiang L, Cheng Z. Small-animal PET imaging of human epidermal growth factor receptor positive tumor with a ${ }^{64} \mathrm{Cu}$ labeled Affibody protein. Bioconjug Chem. 2010;21:947-54.

14. Miao Z, Ren G, Liu H, Qi S, Wu S, Cheng Z. PET of EGFR expression with an ${ }^{18}$ F-labeled Affibody molecule. J Nucl Med. 2012;53:1110-8.

15. Malmberg J, Tolmachev $V$, Orlova A. Imaging agents for in vivo molecular profiling of disseminated prostate cancer-targeting EGFR receptors in prostate cancer: comparison of cellular processing of $\left.{ }^{111} \mathrm{In}\right]$-labeled Affibody molecule Z(EGFR:2377) and cetuximab. Int J Oncol. 2011:38:1137-43.

16. Tolmachev V, Rosik D, Wållberg H, Sjöberg A, Sandström M, Hansson M, et al. Imaging of EGFR expression in murine xenografts using sitespecifically labelled anti-EGFR ${ }^{111}$ In-DOTA-Z EGFR:2377 Affibody molecule: aspect of the injected tracer amount. Eur J Nucl Med Mol Imaging. 2010;37:613-22.

17. Tichauer KM, Diop M, Elliott JT, Samkoe KS, Hasan T, Lawrence KS, et al. Accounting for pharmacokinetic differences in dual-tracer receptor density imaging. Phys Med Biol. 2014;59:2341-51.

18. Gunneriusson $E$, Nord K, Uhlén M, Nygren PÅ. Affinity maturation of a Taq DNA polymerase specific Affibody by helix shuffling. Protein Eng. 1999;12:873-8.

19. Cheng Q, Stone-Elander S, Arner ES. Tagging recombinant proteins with a Sel-tag for purification, labeling with electrophilic compounds or radiolabeling with ${ }^{11} \mathrm{C}$. Nat Protoc. 2006;1:604-13.

20. Wållberg H, Grafström J, Cheng Q, Lu L, Martinsson Ahlzén HS Samén E, et al. HER2-positive tumors imaged within 1 hour using a site-specifically ${ }^{11} \mathrm{C}$-labeled Sel-tagged Affibody molecule. J Nucl Med. 2012;53:1446-53.

21. Cleta Croce A, Ferrigno A, Vairetti M, Bertone R, Freitas I, Bottiroli G. Autofluorescence spectroscopy of rat liver during experimental transplantation procedure. An approach for hepatic metabolism assessment Photochem Photobiol Sci. 2005:4:583-90.

22. Mogensen CE, Solling K. Studies on renal tubular protein reabsorption: partial and near complete inhibition by certain amino acids. Scand J Clin Lab Invest. 1977;37:477-86.

23. Gunn RN, Gunn SR, Cunningham VJ. Positron emission tomography compartmental models. J Cereb Blood Flow Metab. 2001;21:635-52.

24. Maeda $H$, Nakamura $H$, Fang J. The EPR effect for macromolecular drug delivery to solid tumors: improvement of tumor uptake, lowering of systemic toxicity, and distinct tumor imaging in vivo. Adv Drug Deliv Rev. 2013:65:71-9.

25. Hlatky L, Olesiak M, Hahnfeldt P. Measurement of potential doubling time for human tumor xenografts using cytokinesis block method. Cancer Res. 1996;56:1660-3

26. Ehling J, Theek B, Gremse F, Baetke F, Möckel D, Maynard J, et al. Micro-CT imaging of tumor angiogenesis: quantitative measures describing micromorphology and vascularization. Am J Pathol. 2014;184:431-41.

27. Bremer C, Mustafa M, Bogdanov Jr A, Ntziachristos V, Petrovsky A Weissleder R. Steady-state blood volume measurements in experimental tumors with different angiogenic burdens a study in mice. Radiology. 2003;226:214-20

28. Figueiras RG, Padhani AR, Goh VJ, Villanova JC, González SB, Martin CV, et al. Novel oncologic drugs: what they do and how they affect images. Radiographics. 2011;31:2059-91.

29. Cheng Q, Lu L, Grafström J, Olofsson MH, Thorell JO, Samén E, et al. Combining $\left[{ }^{11} \mathrm{C}\right]$-AnxA5 PET imaging with serum biomarkers for improved detection in live mice of modest cell death in human solid tumor xenografts. PLoS One. 2012;7:e42151.

30. Grafström J, Stone-Elander S. Comparison of methods for evaluating radiolabelled Annexin A5 uptake in pre-clinical PET oncological studies. Nucl Med Biol. 2014:41:793-800.

31. Patlak CS, Blasberg RG, Fenstermacher JD. Graphical evaluation of blood-tobrain transfer constants from multiple-time uptake data. J Cereb Blood Flow Metab. 1983;3:1-7

32. Thurber GM, Schmidt MM, Wittrup KD. Antibody tumor penetration: transport opposed by systemic and antigen-mediated clearance. Adv Drug Deliv Rev. 2008:60:1421-34.

33. Schmidt MM, Wittrup KD. A modeling analysis of the effects of molecular size and binding affinity on tumor targeting. Mol Cancer. 2009:8:2861-71.

34. Naumov GN, Bender E, Zurakowski D, Kang SY, Sampson D, Flynn E, et al. A model of human tumor dormancy: an angiogenic switch from the nonangiogenic phenotype. J Natl Cancer Inst. 2006;98:316-25.

35. Gainkam LO, Huang L, Caveliers V, Keyaerts M, Hernot S, Vaneycken I, et al. Comparison of the biodistribution and tumor targeting of two ${ }^{99 \mathrm{~m}} \mathrm{TC}$ labeled anti-EGFR nanobodies in mice, using pinhole SPECT/micro-CT. J Nucl Med. 2008:49:788-95.

36. Aerts HJ, Dubois L, Perk L, Vermaelen P, van Dongen GA, Wouters BG, et al. Disparity between in vivo EGFR expression and ${ }^{89} \mathrm{Zr}$-labeled cetuximab uptake assessed with PET. J Nucl Med. 2009;50:123-31.

37. Niu G, Li Z, Xie J, Le QT, Chen X. PET of EGFR antibody distribution in head and neck squamous cell carcinoma models. J Nucl Med. 2009;50:1116-23.

38. Tichauer KM, Samkoe KS, Sexton KJ. In vivo quantification of tumor receptor binding potential with dual-reporter molecular imaging. Mol Imaging Biol. 2012;14:584-92.

39. Ginovart N. Imaging the dopamine system with in vivo [11C]raclopride displacement studies: understanding the true mechanism. Mol Imaging Biol. 2005;7:45-52.

40. Sorkin A, Goh LK. Endocytosis and intracellular trafficking of ErbBs. Exp Cell Res. 2009;315:683-96.

41. Pu YS, Huang CY, Kuo YZ, Kang WY, Liu G, Huang AM, et al. Characterization of membranous and cytoplasmic EGFR expression in human normal renal cortex and renal cell carcinoma. J Biomed Sci. 2009;16:82.

42. Noske A, Schwabe M, Weichert W, Darb-Esfahani S, Buckendahl AC, Sehouli J, et al. An intracellular targeted antibody detects EGFR as an independent prognostic factor in ovarian carcinomas. BMC Cancer. 2011;11:294.

43. Bahce I, Smit EF, Lubberink M, van der Veldt AA, Yaqub M, Windhorst AD, et al. Development of $\left[{ }^{11} \mathrm{C}\right]$ erlotinib positron emission tomography for in vivo evaluation of EGF receptor mutational status. Clin Cancer Res. 2013;19:183-93. 
44. Johansson L, Chen C, Thorell JO, Fredriksson A, Stone-Elander S, Gafvelin G, et al. Exploiting the 21st amino acid-purifying and labeling proteins by selenolate targeting. Nat Methods. 2004;1:61-6.

45. Arnér ES, Sarioglu H, Lottspeich F, Holmgren A, Böck A. High-level expression in Escherichia coli of selenocysteine-containing rat thioredoxin reductase utilizing gene fusions with engineered bacterial-type SECIS elements and co-expression with the selA, selB and selC genes. J Mol Biol. 1999;292:1003-16.

46. Cheng Q, Lu L, Grafström J, Olofsson MH, Thorell JO, Samén E, et al. Sitespecifically ${ }^{11} \mathrm{C}$-labeled Sel-tagged annexin $\mathrm{A} 5$ and a size-matched control for dynamic in vivo PET imaging of protein distribution in tissues prior to and after induced cell death. Biochim Biophys Acta. 1830;2013:2562-73.

47. Larsen P, Ulin J, Dahlström K, Jensen M. Synthesis of $\left[{ }^{11} \mathrm{C}\right]$ iodomethane by iodination of [ $\left.{ }^{11} \mathrm{C}\right]$ methane. Appl Radiat Isot. 1997;48:153-7.

48. Söderberg O, Gullberg M, Jarvius M, Ridderstråle K, Leuchowius K, Jarvius J, et al. Direct observation of individual endogenous protein complexes in situ by proximity ligation. Nat Methods. 2006;3:995-1000.

49. Aubele M, Spears M, Ludyga N, Braselmann H, Feuchtinger A, Taylor KJ, et al. In situ quantification of HER2-protein tyrosine kinase 6 (PTK6) proteinprotein complexes in paraffin sections from breast cancer tissues. $\mathrm{Br} J$ Cancer. 2010;103:663-7.

50. Gu GJ, Lund H, Wu D, Blokzijl A, Classon C, von Euler G, et al. Role of individual MARK isoforms in phosphorylation of tau at $\mathrm{Ser}^{262}$ in Alzheimer's disease. Neuromol Med. 2013;15:458-69.

51. Adams MC, Turkington TG, Wilson JM, Wong TC. A systematic review of the factors affecting accuracy of SUV measurements. Am J Roentgenol. 2010;195:310-20.

\section{Submit your manuscript to a SpringerOpen ${ }^{\circ}$ journal and benefit from:}

- Convenient online submission

- Rigorous peer review

- Immediate publication on acceptance

- Open access: articles freely available online

- High visibility within the field

- Retaining the copyright to your article

Submit your next manuscript at $\boldsymbol{s p r i n g e r o p e n . c o m ~}$ 